\title{
Malaysian National Philosophy of Education Scale: PCA and CFA Approaches
}

\author{
Shafeeq Hussain Vazhathodi Al-Hudawi ${ }^{1}$, Mohammed Borhandden Musah ${ }^{1} \&$ Rosy Lai Su Fong ${ }^{1}$ \\ ${ }^{1}$ Faculty of Education in Universiti Teknologi Malaysia, Johor Bahru, Malaysia \\ Correspondence: Shafeeq Hussain Vazhathodi Al-Hudawi, Faculty of Education in Universiti Teknologi \\ Malaysia, Skudai, 81310, Johor Bahru, Malaysia. Tel: 60-01-0515-4971. E-mail: shafeeq@utm.my
}

Received: June 5, 2014 Accepted: August 6, 2014 Online Published: August 22, 2014

doi:10.5539/ass.v10n18p163 URL: http://dx.doi.org/10.5539/ass.v10n18p163

\begin{abstract}
This study assesses the psychometric properties of the Malaysian National Philosophy of Education (NPE) Scale. The study argues on the grounds of literature obtained that since the emergence of NPE no empirical validation of the scale was performed. As such, the study sampled 230 participants in secondary schools in Kuching, Malaysia to develop and validate the scale. The results demonstrate that the NPE comprises eight distinct factors. The fit statistics of the NPE eight-factor model demonstrate that the model fitted the data. This quantitative scale is deemed as the first of its kind to device the NPE instrument quantitatively, assess the psychometric properties, and establish evidence for composite reliability, construct, convergent, and discriminant validities of the instrument across selected secondary schools. Theoretically, the NPE quantitative measures initiated and contributed a new body of knowledge to the NPE in the context of Malaysia other than the conceptual dimensions proposed by Ministry of Education. Practically, the results provided school principals and the Ministry of Education with appropriate tools to assess the extent to which school teachers translate and infuse the ideas of the NPE in the day-to-day lesson delivery.
\end{abstract}

Keywords: confirmatory factor analysis, national philosophy of education, principal component analysis, validity

\section{Introduction}

A coherent vision and goals are vital to any educational efforts in any given nation. Generally, the philosophy of education provides essential principles and guidelines, with respect to teaching and learning, intellectual and moral building and education goals (Mohamed, 1990). Educational assumptions and practices are structured by these principles and are core to formulating "the aims of education, and the functions of educational institutions in a society" (Butler, 1968, p. 486).

In view of this importance, the Ministry of Education in Malaysia introduced the National Philosophy of Education (NPE) in 1988. The NPE was formed in line with the Rukun Negara (National Principles) (Ministry of Education 2001). The National Principles or National Philosophy (i.e. Believe in God, loyalty to King and country, upholding the constitution, the role of law and good behaviours and morality) were laid down by royal proclamation in 1970, with the aim of creating harmony and unity among the various races in Malaysia (Ministry of Education, 2013).

The formulation of the NPE was done given the background of various education policies and acts (Education Ordinance, 1957; Education Act, 1961; Razak's Report, 1956; Rahman Talib Report, 1960; Special Cabinet Committee Report, 1979) and taking careful account of political, social and economic needs and satisfaction of Malaysia's multi-ethnic citizens (Hashim, 2004; Sang, 2008). In other words, the combination of two core dimensions; how important education is for everyone and the received wisdom on the role of education had led to the birth of NPE in the educational sector (Allen, 1988).

The NPE acts as the basis for building a united and progressive society and nation. According to Ministry of Education (2008), NPE reads:

Education in Malaysia is an on-going effort towards further developing the potential of individuals in a holistic and integrated manner, so as to produce individuals who are intellectually, spiritually, emotionally and physically balanced and harmonious based on a firm belief in and devotion to God. Such an effort is designed to produce 
Malaysian citizens who are knowledgeable and competent, who possess high moral standards and who are responsible and capable of achieving a high level of personal well-being as well as being able to contribute to the betterment of the family, society and the nation at large. (p. ix).

NPE can be translated into the four national educational objectives, which are: "(a) to produce a loyal and united Malaysian nation, (b) to produce a faithful, well-mannered, knowledgeable, competent and prosperous individuals, (c) to produce the nation's human resource for development needs and (d) to provide educational opportunities for all Malaysians" (Ministry of Education, 2008, p. xii).

Furthermore, the formulation of the NPE was based on six basic factors; religion, society, politics, economy, individuals and globalisation (Ee, 1996).

With regard to education, the important role of the NPE as general aims of education in Malaysia, and its direct implication on the school curriculum are evident in the latest KSSR (Kurikulum Standard Sekolah Rendah) [Primary School Standard-based Curriculum] introduced in 2011 (Note 1), KBSR (Kurikulum Bersepadu Sekolah Rendah) [Malaysian National Primary School Syllabus], first introduced in 1982 and reviewed in 2003 and KBSM (Kurikulum Bersepadu Sekolah Menengah) [Malaysian National Secondary School Syllabus] introduced in 1988 (Ee, 1996; Lee, 1999).

Accordingly, both KBSR and KBSM took on a whole new course and holistic approach to human development focusing on child centred approaches. Student participation was incorporated into the teaching and learning activities, both classroom and co-curricular (Ahmad, 1998).

The KBSR aims at making learning to be gained through a variety of experiences, such as group learning depending on the skills, interests and ability of the differentiated group of students. The teaching and learning process should, as far as possible, be improved through the use of local prototype materials and orientations to reflect a truly Malaysian curriculum (Ahmad, 1998). In other words, specific aspects of education, such as moral values, patriotism, science and technology, language, environmental education, and study skills should be infused across the subject disciplines, with the purpose of consolidating these aspects which need further emphasis (International Bureau of Education, 2005).

The underlying philosophy of KBSR is a "child-centred curriculum" which recognizes the importance of individual differences, individual achievement and emphasizes the overall development of the child (Azizah, 1987).

KBSM is a continuation of the KBSR, which aims at providing general education until the 11th year of schooling, through the offering of core subjects, and elective subjects to enable students to make choices in selecting subjects of their interest. At the lower secondary level, KBSM retains the structure and subject offerings, except that the choice of electives of pre-vocational subjects is eliminated. Instead of a new subject, "Life skills" is introduced as part of the core, taken by all students. The contents comprise some basic elements of Industrial Arts, Home Economics, Commerce and Agricultural science, to enable students to acquire manipulative skills in coping with their day-to-day lives.

It is observed that major changes occurred at the upper secondary level. The KBSM aims to continue providing general education (implying that specialization is to be deferred to the pre-university level, which is beyond what is covered by the KBSM). As such, the eleven years of schooling (six years elementary and five years secondary) would at a go prepare students for the job market as well as to further their education to higher levels. Students are thus no more streamed into specialized areas, (Arts, Science, Technical or Vocational streams), although they still have the option to have subject concentration through their choice of elective subjects. This is because the upper secondary curriculum consists of core subjects required of all students (i.e. general education), and four groups of subjects from four areas (Humanities, Science, Technical and Vocational, and Islamic Education). Students are allowed to choose their electives from two of the four areas. This may also mean paving the way for the ultimate abolishment of the technical and vocational schools.

In 1988, the Integrated Secondary School Curriculum (referred to as KBSM) was introduced as a continuation of the curriculum reform efforts at secondary level. Wilson (1977) argued that integrating educational philosophy across curriculum and identifying means of actualising the components of philosophy in the educational processes is paramount to any educational success.

The emphasis of the new secondary school curriculum is on "integration", which stresses the teaching of language and values across the curriculum (Abdullah \& Kumar, 1990). New subjects like Moral Education (for non-Muslim students), Islamic Studies (for Muslim students) and Living Skills were included in the integrated curriculum. Another distinctive feature of KBSM is that students are no longer streamed into Arts or Science 
streams. The new curriculum has done away with early specialization allowing students to choose subjects from different groups of electives. Sang (2008) indicated changes occurring in school curriculum that were associated with the objectives of the NPE. The KBSR and KBSM are anticipated to be able to reflect the NPE. But, quantitative investigations to validate NPE instruments were not found across NPE related literature. Let alone the absence of empirical studies on NPE dimensions, the educational reform initiatives took place in Malaysia also rendered more emphasis on public examination results rather than the basic ideas structured the NPE in the school context. Molly (1999, p. 96) clearly stressed that:

Much of the public discourse on school effectiveness in Malaysia has focused solely on public examination results despite the fact that the national philosophy of education stresses the importance of the development of an all-around individual with respect to intellectual, emotional, spiritual and physical development.

In general, NPE elements are categorised into fifteen dimensions; (15) sub-groups as stated in the manual entitled [National Philosophy of Education, Goal and Mission] (Falsafah Pendidikan Kebangsaan, Matlamat dan Misi). The sub-groups of the NPE included (a) education is an on-going effort, (b) developing the potential of individual, (c) develop the potential in a holistic and integrated manner, (d) a balanced and harmonious individual, (e) intellectual dimension, (f) spiritual dimension, (g) emotional dimension, (h) physical dimension, (i) firm belief in and devotion to God, (j) Malaysian citizens who are knowledgeable, (k) Malaysian citizens who are competent, (l) Malaysian citizens who possess high moral standard, (m) Malaysian citizens who are responsible, (n) Malaysian citizens who are capable of achieving a high level of personal well-being, and (o) Malaysian citizens who are able to contribute to the betterment of the family, society and the nation. These dimensions are the underlying key concepts that this study attempted to develop quantitative measures based on the key concepts outlined in the manual (Ministry of Education, 2001).

Other that al-Hudawi, Fong, Musah, and Tahir's (2014) study, studies that empirically investigated all the dimensions of the NPE in the secondary school context were not found in the literature. A handful of researchers studied certain dimensions of the NPE such as 'How effective should Malaysian national education philosophy be?' (Hassan \& Abiddin, 2010), 'the holistic development' (Ismail \& Hassan, 2009b), 'firm belief in God' (Ismail, Aida, Wan, Ramlah, Rosini, \& Hapsah, 2009a) and 'academic productivity and the impact of the national education philosophy in higher education institutions as viewed by Malaysian academics' (Hassan, 2006). All these studies did not attempt to develop quantitative measures rather than investigating the implementation, teacher belief about the NPE and effectiveness of NPE based on the selected dimensions of NPE. Even the NPE actualization level itself remained vague. Given the absence of the quantitative measures for NPE dimensions, this study poses the following research question and hypothesis:

Research question: How many interpretable and reliable factors constitute NPE across the selected secondary schools in Kuching?

Research hypothesis: NPE factors indexed through the application of principal component analysis (PCA) are valid and reliable.

\section{Methodology}

\subsection{Sample}

This study employed stratified random sampling technique to collect data from the participant of selected secondary schools in Kuching, Malaysia. In total, 300 survey questionnaires addressing components of NPE were distributed to secondary school teachers across selected secondary schools in Kuching. Participants were asked to express their level of agreement or disagreement with the propositions in the survey questionnaires. Of the distributed survey questionnaires, 230 were returned, representing $76.66 \%$ of response rate.

\subsection{Instrumentation}

The process of data collection on NPE in this study used a survey questionnaire. The questionnaire comprises both survey instruments and demographic data. Apart from demographic information of the participants (gender, race, and religion), the questionnaire comprised 85 measures seeking information on 15 sub-dimensions underlie NPE (Ministry of Education, 2008; Sang, 2008). The researchers devised the measures of NPE through extensive reading on the related literature on NPE from Ministry of Education handbook and other relevant sources.

The measures in the NPE have been divided into fifteen constructs in accordance with the elaboration provided in the handbook of Ministry of Education and then further broken down into eighty five (85) measures al-Hudawi et al. (2014) as outlined in Table 1. 
Table 1. Background of items according to variables investigated

\begin{tabular}{ll}
\hline Variables Measured & Measure \\
\hline On-going effort & Q1-Q3 \\
Potential individual development & Q4-Q8 \\
Holistic and integrated potential development & Q9-Q11 \\
Balanced and harmonious individual & Q12-Q20 \\
Intellectual dimension & Q21-Q29 \\
Spiritual dimension & Q30-Q36 \\
Emotional dimension & Q37-Q42 \\
Physical dimension & Q43-Q48 \\
Belief and devotion to God & Q49-Q55 \\
Knowledgeable citizens & Q56-Q58 \\
Competent citizens & Q59-Q62 \\
High moral citizens & Q63-Q67 \\
Responsible citizens & Q68-Q73 \\
Achieving high personal well-being & Q74-Q76 \\
Contributive citizens & Q77-Q85 \\
\hline
\end{tabular}

Each measure was revised by adding personal pronoun, so that respondents are able to understand and make logical sense of the measures. Participants were required to rate each measure from 0 (not at all) to 10 (fully possessed) using formula suggested by (Arieh, 1978). This scale was then recoded on a 5-point Likert type scale for interpretability of the dataset. The recoded scale is interpreted as: $0-2=$ not at all (1), 3-4=rarely possess (2), 5-6=No answer (3), 7-8=somehow possess (4) and 9-10=fully possess (5).

\section{Data Analysis and Results of the Study}

The data collected were analysed following a three-step procedure. First, PCA using predictive analytics software (PASW) version 20.0 software was used to test the underlying factors and validate measures constituted NPE factors. This was then followed by the application of confirmatory factor analysis (CFA) using AMOS version 21.0 software to assess and confirm the validity of the constructs (Arbuckle, 2008). Finally, assessment of construct validity through average variance extracted (AVE) and construct reliability through composite reliability index (CRI) was performed.

\subsection{Unit of Analysis}

Table 2. Frequency and percentages of respondents' gender, race and religion

\begin{tabular}{lll}
\hline Variable & Frequency & $\mathbf{\%}$ \\
\hline Gender & 146 & 63.5 \\
Male & 84 & 36.5 \\
Female & 230 & 100 \\
Total & & \\
Race & 80 & 34.8 \\
Malay & 94 & 40.9 \\
Chinese & 56 & 24.3 \\
Others & 230 & 100 \\
Total & & \\
Religion & 88 & 38.3 \\
Muslim & 80 & 34.8 \\
Christian & 7 & 3.0 \\
Atheist & 3 & 1.3 \\
Others & 230 & 100 \\
Total & & \\
\hline
\end{tabular}

The results of the descriptive analysis indicated that $(\mathrm{n}=146,63.5 \%)$ of the participants were males, while $(\mathrm{n}=84$, $36.5 \%$ ) were females. With reference to participants' race, the analysis showed that the majority of participants 
were Chinese ethnic group ( $\mathrm{n}=94,40.9 \%)$. This was followed by the Malay ethnic group $(\mathrm{n}=80,34.8 \%)$. In addition, participants who were classified as other ethnic group were the smallest number in terms of proportions of participation $(\mathrm{n}=56,24.3 \%)$.

Furthermore, the analysis demonstrated that the majority $(\mathrm{n}=88,38.3 \%)$ of the participants, who participated in the study were Muslims. Followed by participants, who identified themselves as Christians ( $\mathrm{n}=80,34.8 \%)$. Then participants who identified themselves as Buddhists $(\mathrm{n}=7,3.0 \%)$. Finally, participants who ascribed themselves as others $(\mathrm{n}=3,1.3 \%)$ were the smallest denominations represented in this study. Table 2 depicts the details.

\subsection{Principal Component Analysis of NPE Constructs}

Prior to the application of PCA to test the underlying structures of NPE dimensions, a reliability test was performed to assess the internal consistency of the pool of the items constituted NPE factors. The results of reliability analysis revealed overall Cronbach's alpha of .95 . This value is greater than 0.70 , and therefore presents a substantial support for the internal consistency of the items (Morgan, Leech, \& Gloeckner, 2007; Nunnally, 1978).

A PCA was then performed on the constructs. The analysis involved an iterative process to reach the final solution, whereby items that did not contribute significantly and practically to the extracted factors were automatically discarded. Furthermore, factors with eigenvalues of 1 or greater were considered as good factors, and therefore retained. Given a rule of thumb as such, a number of factors were extracted from the pool of items. The correlation matrix table yielded more than 3 correlations greater than 0.30 . The measures of sampling adequacy (MSA) requirement of ( $\geq .50)$ were also satisfied. Thus, the anti-image correlations ranged between .53 and .96. Furthermore, all communalities were greater than .50 (ranged between .51 and .98 ), which indicates fulfilment of the requirement. Items that loaded at .40 or greater on a factor and were more than 2 were deemed as representative of a valid factor.

Moreover, the analysis revealed fifteen interpretable factors with eigenvalues of the first eight factors greater than one. The extracted factors accounted for $75.85 \%$ of total variance explained in the constructs analysed. Interestingly, the degree of inter-correlation among the items also reached a satisfied level. Bartlett's test of Sphericity was statistically significant $\chi^{2}(3570)=1845.88, \rho<.001, \mathrm{KMO}=.92$. More specifically, the analysis revealed fifteen interpretable factors. However, only eight factors were returned for further analysis, since each factor contained more than two items and exhibited eigenvalue $\geq 1$ or greater.

Factor one, which was initially labelled as potential individual development contained valid items. Of the five items initially hypothesised on this factor, four items were accurately loaded under this factor. To expatiate upon this result, it is clearly evident that the items exhibited practical and statistical significant loading (Hair, Anderson, Tatham, \& Black, 2010). Item QB4 however, was omitted for exhibiting factorial complexity on two factors.

Regarding factor two, which was labelled as spiritual dimension, seven items were initially hypothesised on this factor. Of the seven items, five items were accurately loaded under their hypothesised factor except items QF6 and QF7 which were highly weighted on different factors. Consequently, they were discarded from further analysis.

Factor three was labelled as high moral citizens, and was initially indexed by five items. However, two Items were discarded due to the issue of factorial complexity on two different factors and low loading issue $(<.40)$. The loadings of the retained three items demonstrated practical and statistical significance (Hair et al., 2010). Consequently, the factor was retained.

Pertaining to factor four which initially contained nine items that represented contributive citizens. Of the nine items initially hypothesised on this factor, seven items substantially loaded on the factor. However, items QO1 and QO8, which exhibited factorial complexity, were discarded from further analysis.

Three items were initially hypothesised on factor five, which was labelled as knowledgeable citizens. Interestingly, all three items were accurately loaded under its hypothesised factor showing neither factorial complexity nor low loading issue associated with this factor.

With regards to factor six, labelled as intellectual dimension, nine items were initially hypothesised on this factor. However, only three items were accurately weighted on this factor. While items QE1, QE4, QE3 and QE6 exhibited factorial complexity, items QE2 and QE5 associated with low loading issues. Therefore, they were discarded from further analysis.

Factor seven, which represented physical dimension, was initially constituted of six items. Of the six items, only 
three items were accurately loaded on their hypothesised factor. Items QH1, QH2 and QH6 exhibited factorial complexity on different factors. Consequently, they were dropped from further analysis.

The final factor which was labelled as balanced and harmonious individual was initially hypothesised on nine items. Of the nine items, only three items were properly loaded on their hypothesised factor. While items QD1, QD2 and QD9, demonstrated low loading issues, items QD3 and QD7 exhibited factorial complexity related issues. Therefore, they were discarded from further analysis. The per factor internal consistency of the eight retained factors demonstrated reasonable reliability indexes for all eight factors, ranging from .61 through .95 respectively.

In addition, construct validity, which was employed using total variance explained by each factor in NPE construct showed that the eight factors composing the NPE construct are valid. The construct validity index for the eight factors of NPE were $69.63 \%, 83.39 \%, 76.10 \%, 68.45 \%, 76.75 \%, 74.66 \%, 54.25 \%$, and $62.36 \%$ respectively. As such, construct validity criteria was met (Hair et al., 2010). These results address the research question posed earlier with the finding that there were reliable and interpretable factors of NPE across selected secondary schools in Kuching. The extracted factors along with their items are shown in Table 3.

Table 3. NPE factor loading, anti-image, means, reliability, eigenvalues, variance explained and standard deviation

\begin{tabular}{|c|c|c|c|c|c|c|c|c|c|c|c|c|}
\hline \multirow{2}{*}{ No. } & \multirow{2}{*}{ Item } & \multicolumn{8}{|c|}{ Factor loading } & \multirow{2}{*}{ MSA } & \multirow{2}{*}{$\mathbf{M}$} & \multirow{2}{*}{ SD } \\
\hline & & IPD & $\mathrm{SD}$ & HMC & $\mathrm{CC}$ & $\mathrm{KC}$ & ID & PHD & BHI & & & \\
\hline QB2 & $\begin{array}{l}\text { My student puts } \\
\text { effort to develop } \\
\text { his/her } \\
\text { potential. }\end{array}$ & .79 & & & & & & & & .94 & 3.97 & 1.01 \\
\hline QB3 & $\begin{array}{l}\text { My student is } \\
\text { given the } \\
\text { opportunity to } \\
\text { develop his/her } \\
\text { potential. }\end{array}$ & .72 & & & & & & & & .91 & 3.70 & 1.10 \\
\hline QB1 & $\begin{array}{l}\text { My student } \\
\text { knows there are } \\
\text { potentials in } \\
\text { him/her to be } \\
\text { developed. }\end{array}$ & .67 & & & & & & & & .91 & 3.92 & 1.01 \\
\hline QB5 & $\begin{array}{l}\text { My student has } \\
\text { potential to } \\
\text { success in life. }\end{array}$ & .66 & & & & & & & & .93 & 4.08 & .94 \\
\hline QF2 & $\begin{array}{l}\text { My student } \\
\text { recognizes that } \\
\text { there is a } \\
\text { Creator. }\end{array}$ & & .87 & & & & & & & .90 & 4.24 & 1.10 \\
\hline QF1 & $\begin{array}{lr}\text { My } & \text { student } \\
\text { realizes } & \text { that } \\
\text { there } & \text { is a } \\
\text { Creator. } & \end{array}$ & & .84 & & & & & & & .92 & 4.29 & 1.09 \\
\hline QF5 & $\begin{array}{l}\text { My student is } \\
\text { aware and } \\
\text { acknowledge } \\
\text { own } \\
\text { responsibility in } \\
\text { God. }\end{array}$ & & .83 & & & & & & & .93 & 4.25 & 1.08 \\
\hline QF3 & $\begin{array}{l}\text { My student } \\
\text { appreciates } \\
\text { things given by } \\
\text { the Creator. }\end{array}$ & & .81 & & & & & & & .87 & 4.29 & 1.02 \\
\hline QF4 & $\begin{array}{l}\text { My student is } \\
\text { thankful } \\
\text { things given by } \\
\text { God. }\end{array}$ & & .78 & & & & & & & .91 & 4.44 & .92 \\
\hline QL5 & My student & & & .68 & & & & & & .94 & 4.17 & .93 \\
\hline
\end{tabular}




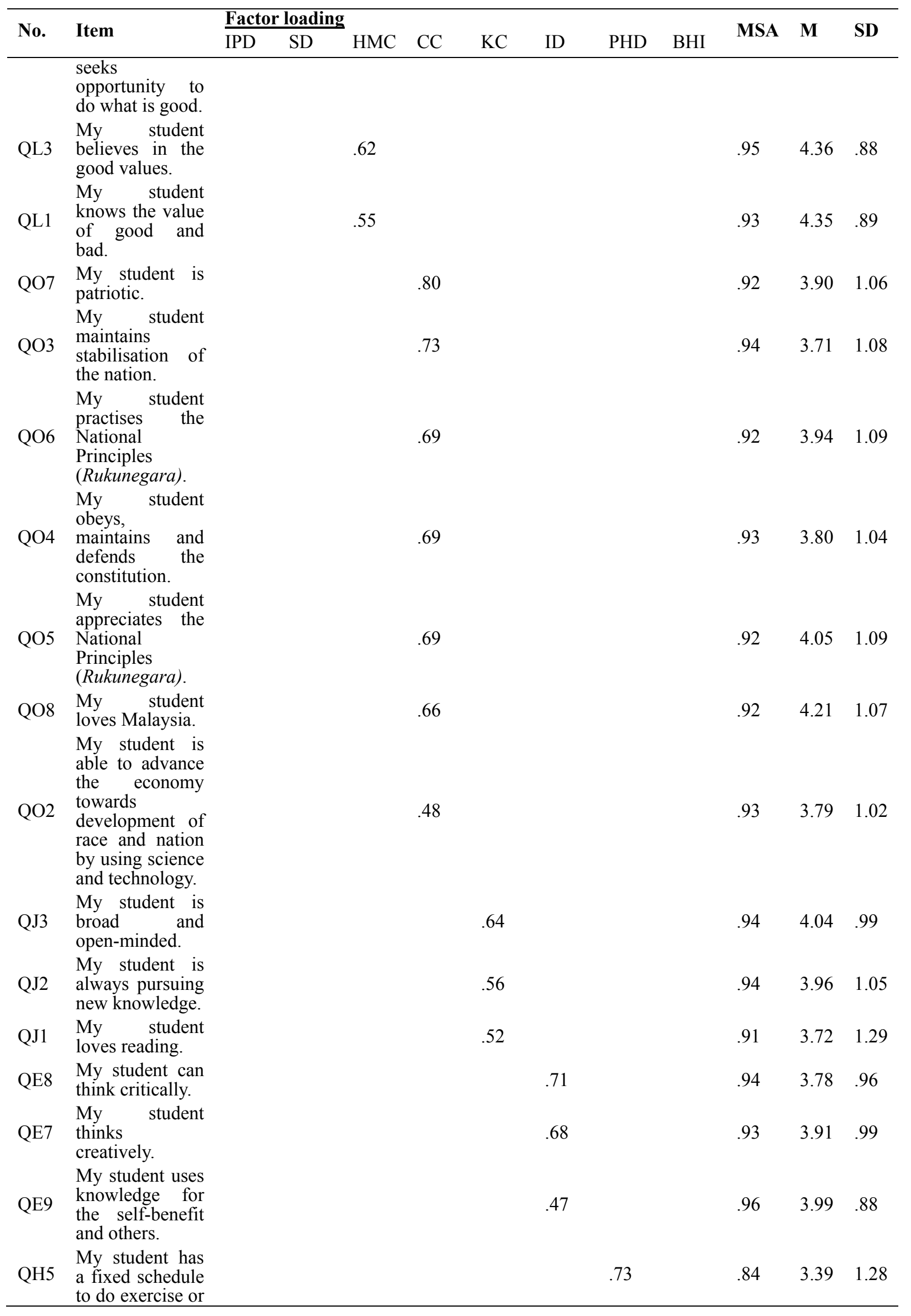




\begin{tabular}{|c|c|c|c|c|c|c|c|c|c|c|c|c|}
\hline \multirow{2}{*}{ No. } & \multirow{2}{*}{ Item } & \multicolumn{8}{|c|}{ Factor loading } & \multirow{2}{*}{ MSA } & \multirow{2}{*}{$\mathbf{M}$} & \multirow{2}{*}{ SD } \\
\hline & & IPD & SD & HMC & $\mathrm{CC}$ & $\mathrm{KC}$ & ID & PHD & BHI & & & \\
\hline QH4 & $\begin{array}{l}\text { sport. } \\
\text { My student likes } \\
\text { to exercise. }\end{array}$ & & & & & & & .73 & & .86 & 4.06 & 1.00 \\
\hline QH3 & $\begin{array}{l}\text { My student } \\
\text { develops his/her } \\
\text { technical talent } \\
\text { and skill (e.g. } \\
\text { Sport). }\end{array}$ & & & & & & & .62 & & .93 & 4.03 & 1.00 \\
\hline QH2 & $\begin{array}{l}\text { My student has } \\
\text { ample time for } \\
\text { leisure (outdoor } \\
\text { activity). }\end{array}$ & & & & & & & .46 & & .51 & 4.11 & 2.87 \\
\hline QD8 & $\begin{array}{l}\text { My student } \\
\text { exhibits a stable } \\
\text { emotion. }\end{array}$ & & & & & & & & .69 & .89 & 3.91 & .98 \\
\hline QD5 & $\begin{array}{l}\text { My student feels } \\
\text { peace all the } \\
\text { time. }\end{array}$ & & & & & & & & .63 & .91 & 3.59 & 1.13 \\
\hline QD6 & $\begin{array}{l}\text { My student is } \\
\text { physically } \\
\text { healthy and fit. }\end{array}$ & & & & & & & & .49 & .91 & 3.95 & .92 \\
\hline \multicolumn{2}{|c|}{ Eigenvalue } & 35.15 & 5.82 & 3.58 & 2.72 & 2.23 & 2.06 & 1.86 & 1.81 & & & \\
\hline \multicolumn{2}{|c|}{ Construct Validity } & 69.63 & 83.39 & 76.10 & 68.45 & 76.75 & 74.66 & 54.25 & 62.36 & & & \\
\hline \multicolumn{2}{|c|}{ Construct Reliability } & .85 & .95 & .84 & .92 & .84 & .83 & .61 & .70 & & & \\
\hline
\end{tabular}

Note: $\mathrm{IPD}=$ potential individual development, $\mathrm{SD}=$ spiritual dimension, $\mathrm{HMC}=$ high moral development, $\mathrm{CC}=$ contributive citizens, $\mathrm{KC}=$ knowledgeable citizens, $\mathrm{ID}=$ intellectual dimension, $\mathrm{PHD}=$ physical dimension and $\mathrm{BHI}=$ balanced and harmonious individuals.

\subsection{Parallel Analysis of NPE Construct}

Table 4. Comparison of PCA and PA eigenvalues for data from NPE construct

\begin{tabular}{llll}
\hline Component no. & Actual eigenvalue from PCA & Criterion eigenvalue from PA & Decision \\
\hline 1 & 35.15 & 2.46 & Accept \\
2 & 5.82 & 2.36 & Accept \\
3 & 3.58 & 2.28 & Accept \\
4 & 2.72 & 2.20 & Accept \\
5 & 2.23 & 2.13 & Accept \\
6 & 2.06 & 1.99 & Accept \\
7 & 1.86 & 1.82 & Accept \\
8 & 1.81 & 1.79 & Accept \\
9 & 1.55 & 1.70 & Rejected \\
10 & 1.48 & 1.66 & Rejected \\
11 & 1.42 & 1.59 & Rejected \\
12 & 1.33 & 1.55 & Rejected \\
13 & 1.22 & 1.48 & Rejected \\
14 & 1.21 & 1.31 & Rejected \\
15 & 1.04 & 1.22 & Rejected \\
\hline
\end{tabular}

An analysis of PA was performed on the NPE constructs to validate the factors extracted through the application of PCA. The analysis revealed that the eigenvalues of the eight factors extracted through the application of PCA were greater than their corresponding eigenvalues of the PA, and were thus significant at $p=0.05$. Therefore, the eight factors were retained for further interpretation. In other words, the decision failed to reject these eight factors, but the other seven factors which earlier did not meet the requirement through the application of PCA 
were further rejected since their eigenvalues were greater than that of PCA values (Franklin, Gibson, Robertson, Pohlmann, \& Fralish, 1995; Horn, 1965; Pallant, 2007). This result further confirmed and cross validated the accuracy and reliability of the eight factors extracted through the application of the PCA. Table 4 demonstrates the details.

\section{Construct Validity}

\subsection{Testing the Validity of NPE Measurement Model}

A CFA was performed to validate the measurement model of the retained factors and further investigate items indexed the retained factors. The analysis demonstrated that the measurement model exhibited reasonable fit statistics to the sample data: $\chi^{2}=1082.84, d f=436, \mathrm{CFI}=.87, \mathrm{TLI}=.86, \mathrm{NFI}=.81, \mathrm{RMSEA}=0.08$ and SRMR $=.06$. Furthermore, the squared multiple correlations (SMC), which indicate how well the observed variables serve as reliable measures of the latent variables were also investigated. It is worth noting that the values of SMC of the NPE measurement model had fulfilled the requirement $\geq .25$ (Schumacker \& Lomax, 2004). The values ranged from .28 to .94 . This provides substantial evidence of the reliability of the parameter estimates.

However, the values of CFI $=.87, \mathrm{TLI}=.86$ and NFI $=.81$ were less than the accepted threshold of $\geq .90$ (Bollen, 1989; Byrne, 2010; Kline, 2011). Since the study sought a better fitting model, Post Hoc modification indices (MIs) were investigated in order to identify a more parsimonious model. As such, the measurement model of NPE was re-estimated.

The MIs investigation disclosed that QO5, QO8, and QF4 were cross loaded with different error terms. The cross-loaded indicator variables were then dropped from the construct. Consequently, the model demonstrated good fit to the observed data: $\chi^{2}=727.07, d f=349, \mathrm{CFI}=.91, \mathrm{TLI}=.90, \mathrm{NFI}=.85, \chi^{2} / d f=2.08, \mathrm{SRMR}=.04$ and RMSEA $=0.06$. Furthermore, all values of critical ratios (CRs) were above the cut-off score of 1.96 . This is an indicative of statistical significance of indicators (Bollen, 1989; Byrne, 2010; Hair et al., 2010; Kline, 2011). Furthermore, the model is consistent with the valid measurement, since the absence of model contamination related issues or being confounded with error term connection is established (Levine, 2005). Figure 1 depicts the details.

In addition, the investigation of the regression weights also provided more supporting information about the loadings' significance (consistency, statistical significance and practical importance) for the indicator variables. All values exhibited a magnitude greater than 1.0. Nonetheless, all CRs were also above the cut-off point of 1.96. This evidence further confirmed the consistency of the theoretical bases in terms of the supported hypothesis. Tables 5 and 6 provide for more details about regression weights with CRs and standardised regression weights.

Table 5. Regression weights with critical ratios

\begin{tabular}{|c|c|c|c|c|c|c|c|}
\hline & & & Estimate & S.E. & C.R. & $\mathrm{P}$ & Label \\
\hline QB2 & $<---$ & IPD & 1.000 & & & & \\
\hline QB3 & $<---$ & IPD & .863 & .077 & 11.177 & $* * *$ & par_1 \\
\hline QB1 & $<---$ & IPD & .906 & .068 & 13.322 & $* * *$ & par_2 \\
\hline QB5 & $<--$ & IPD & .810 & .064 & 12.622 & $* * *$ & par_3 \\
\hline QF2 & $<---$ & SD & 1.000 & & & & \\
\hline QF1 & $<---$ & SD & .970 & .025 & 38.104 & $* * *$ & par_4 \\
\hline QF5 & $<---$ & SD & .814 & .041 & 19.845 & $* * *$ & par_5 \\
\hline QF3 & $<---$ & SD & .852 & .031 & 27.440 & $* * *$ & par_6 \\
\hline QL5 & $<---$ & HMC & 1.000 & & & & \\
\hline QL3 & $<---$ & HMC & .966 & .076 & 12.746 & $* * *$ & par_7 \\
\hline QL1 & $<---$ & HMC & .953 & .077 & 12.431 & $* * *$ & par_8 \\
\hline QO7 & $<---$ & $\mathrm{CC}$ & 1.000 & & & & \\
\hline QO3 & $<---$ & $\mathrm{CC}$ & 1.261 & .093 & 13.496 & $* * *$ & par_9 \\
\hline QO6 & $<---$ & $\mathrm{CC}$ & 1.116 & .094 & 11.817 & $* * *$ & par_10 \\
\hline QO4 & $<---$ & $\mathrm{CC}$ & 1.169 & .089 & 13.077 & $* * *$ & par_11 \\
\hline QO2 & $<---$ & $\mathrm{CC}$ & 1.016 & .088 & 11.544 & $* * *$ & par_12 \\
\hline QJ3 & $<---$ & $\mathrm{KC}$ & 1.000 & & & & \\
\hline QJ2 & $<---$ & $\mathrm{KC}$ & 1.391 & .107 & 13.057 & $* * *$ & par_13 \\
\hline QJ1 & $<---$ & $\mathrm{KC}$ & 1.238 & .113 & 10.916 & $* * *$ & par_14 \\
\hline
\end{tabular}




\begin{tabular}{llllllll}
\hline & & & Estimate & S.E. & C.R. & P & Label \\
\hline QE8 & $<---$ & ID & 1.000 & & & & \\
QE7 & $<--$ & ID & 1.064 & .099 & 10.736 & $* * *$ & par_15 \\
QE9 & $<---$ & ID & 1.049 & .089 & 11.797 & $* * *$ & par_16 \\
QH5 & $<---$ & PHD & 1.000 & & & & \\
QH4 & $<---$ & PHD & .820 & .103 & 7.936 & $* * *$ & par_17 \\
QH3 & $<--$ & PHD & 1.083 & .115 & 9.389 & $* * *$ & par_18 \\
QH2 & $<---$ & PHD & 1.054 & .121 & 8.715 & $* * *$ & par_19 \\
QD8 & $<---$ & BHI & 1.000 & & & & \\
QD5 & $<---$ & BHI & 1.669 & .232 & 7.201 & $* * *$ & par_20 \\
QD6 & $<--$ & BHI & 1.176 & .173 & 6.781 & $* * *$ & par_21 \\
\hline
\end{tabular}

Table 6. Standardized regression weights

\begin{tabular}{|c|c|c|c|}
\hline & & & Estimate \\
\hline QB2 & $\begin{array}{l}<--- \\
\end{array}$ & IPD & .857 \\
\hline QB3 & $<---$ & IPD & .684 \\
\hline QB1 & $<---$ & IPD & .782 \\
\hline QB5 & $<---$ & IPD & .750 \\
\hline QF2 & $<---$ & SD & .975 \\
\hline QF1 & $<---$ & SD & .959 \\
\hline QF5 & $<---$ & SD & .815 \\
\hline QF3 & $<---$ & SD & .900 \\
\hline QL5 & $<---$ & HMC & .796 \\
\hline QL3 & $<---$ & HMC & .810 \\
\hline QL1 & $<---$ & HMC & .791 \\
\hline QO7 & $<---$ & $\mathrm{CC}$ & .727 \\
\hline QO3 & $<---$ & $\mathrm{CC}$ & .900 \\
\hline QO6 & $<---$ & $\mathrm{CC}$ & .790 \\
\hline QO4 & $<---$ & $\mathrm{CC}$ & .871 \\
\hline QO2 & $<---$ & $\mathrm{CC}$ & .772 \\
\hline QJ3 & $<---$ & $\mathrm{KC}$ & .722 \\
\hline QJ2 & $<---$ & $\mathrm{KC}$ & .933 \\
\hline QJ1 & $<---$ & $\mathrm{KC}$ & .745 \\
\hline QE8 & $<---$ & ID & .733 \\
\hline QE7 & $<---$ & ID & .753 \\
\hline QE9 & $<---$ & ID & .839 \\
\hline QH5 & $<---$ & PHD & 617 \\
\hline QH4 & $<---$ & PHD & .648 \\
\hline QH3 & $<---$ & PHD & .852 \\
\hline QH2 & $<---$ & PHD & .739 \\
\hline QD8 & $<---$ & BHI & .535 \\
\hline QD5 & $<---$ & BHI & .779 \\
\hline QD6 & $<---$ & BHI & .669 \\
\hline
\end{tabular}

\subsection{Average Variance Extracted, Composite Reliability Index and Discriminant validity Evaluations}

The assessment clearly indicates that the CRI of all the factors is more than the cut-off value of $\geq .70$, which is desired (Bagozzi \& Burnkrant, 1985; Fornell \& Larcker, 1981). Furthermore, the assessment of the AVE demonstrated that all factors (except for BHI .45) have shown significant threshold values for all NPE factors retained. In other words, the AVE for each factor is $\geq .50$, which further supports the convergent validity of the constructs. 
Table 7. AVE, squared inter-factor covariance and CRI

\begin{tabular}{llllllllll}
\hline Construct & IPD & SD & HMC & CC & KC & ID & PHD & BHI & CRI \\
\hline IPD & $(.59)$ & & & & & & & & .85 \\
SD & .19 & $(.84)$ & & & & & & .95 \\
HMC & .36 & .25 & $(.64)$ & & & & & \\
CC & .25 & .24 & .38 & $(.66)$ & & & & .84 \\
KC & .42 & .10 & .56 & .36 & $(.65)$ & & & & .91 \\
ID & .45 & .25 & .56 & .31 & .53 & $(.60)$ & & & .85 \\
PHD & .23 & .10 & .22 & .37 & .32 & .31 & $(.52)$ & & .81 \\
BHI & .42 & .07 & .32 & .35 & .38 & .40 & .40 & $(.45)$ & .71 \\
\hline
\end{tabular}

Note: Diagonals in parentheses are square roots of the AVE from observed variables (items), whereas off-diagonals are squared inter-factor covariance.

Moreover, discriminant validity was then assessed using the formula suggested by Fornell and Larcker (1981) and Kline (2011), which states that if AVE values are found to be greater than their corresponding inter-factor squared covariance values, then evidence of discriminant validity is established. Thus, the measurement model reflects good construct validity and desirable psychometric properties (Ganguli \& Roy 2011).

Interestingly, the results show that the eight factors exhibited substantial evidence of discriminant validity based on the AVE values observed with their squared inter-factor covariance obtained (Kline, 2011). Succinctly, the measurement model demonstrates adequate and substantial reliability, convergent and discriminant validity. Table 7 depicts the details.

In addition, the graphical investigation of Figure 1 provided supporting evidence of discriminant validity, since the highest inter-factor covariance observed was .75. According to Kline (2011), if inter-correlations of a set of variables that are presumed to measure different factors are not too high $(\leq .85)$, then evidence of discriminant validity is established. The obtained results supported the research hypothesis with the finding that NPE factors indexed through the application of PCA were valid and reliable.

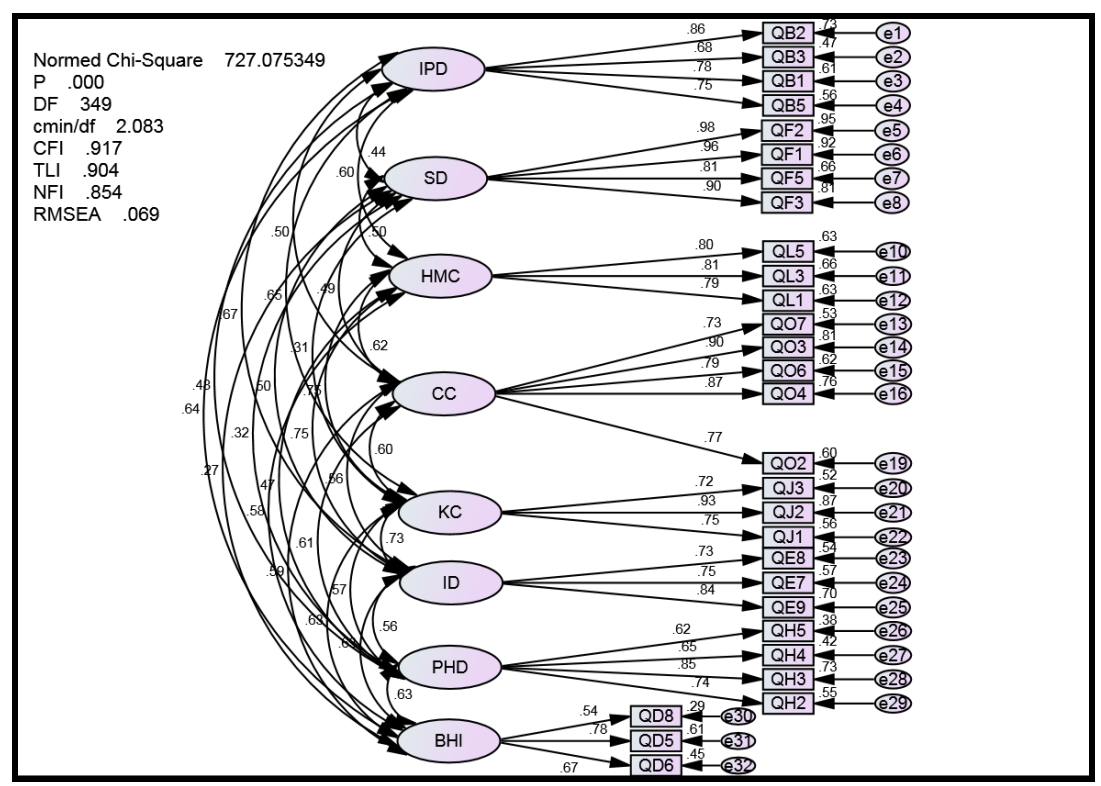

Figure 1. Generated output of NPE eight-factor measurement model

\section{Discussion}

This study was designed to devise quantitative measures for the NPE dimensions and empirically validate the psychometric properties in the context of secondary schools. The empirical findings of the study will serve as a point of departure towards filling a gap in the educational philosophy literature.

The application of PCA in this study demonstrated that NPE in the context of the selected secondary schools is 
represented by eight components. The findings reached the conclusion that the loadings of the clustered items under their extracted factors and the total variance explained by each factor exceeded the acceptable thresholds, indicating statistical significance and practical importance of the retained items, and therefore could be used in future studies, especially in the context of local secondary schools and perhaps in other Asian secondary schools, with particular reference to the NPE. Thus, the components of NPE initially demonstrated substantial high construct validity $(>50 \%)$ after the application of PCA through the examination of the total variance and construct reliability.

The results of PCA together with the results of CFA demonstrate that the NPE construct is an eight-factor model in the context of the selected secondary schools. The proposed measurement model in this preliminary quantitative study was found to exhibit an acceptable fit statistics, thus lending further confirmatory evidence for construct validity.

Furthermore, the results rigorously validated the goodness of fit indices pertaining to the NPE initially validated instrument through the application of various advanced evaluation mechanisms (AVE, CRI, DV and PA). Drawing on the aforementioned results, it is clearly evident that the retained measures demonstrate high regression weights on their respective factors, signifying appropriateness and soundness of the NPE measures.

Moreover, the study provided additional evidence for the usefulness and soundness of the NPE quantitative measures by demonstrating significant critical ratios across all indicator variables in the revised measurement model.

\section{Conclusions}

Given the foregoing discussion, the study examined the factorability and validity of NPE measures, using the conceptual dimensions outlined by the Ministry of Education. The study argued that devising quantitative measures of NPE are necessary since studies on the concept did not disclose any previous quantitative initiative of the measures or testing and validating the factor structure of NPE in the Malaysian educational sector.

The analysis reached the conclusion that the preliminary quantitative measures of NPE in the selected schools exhibit eight valid and reliable factors. The study provided evidence through fit statistics that the eight-factor model fitted the sample data adequately.

\section{Implications of the Findings}

In correspondence with the findings and conclusions emanated from this study, both theoretical and practical implications were drawn. Theoretically, the present study has yielded valid and reliable preliminary measures for measuring NPE dimensions at the secondary school level by conducting empirical analysis using survey data collected from the selected secondary school teachers in the State of Sarawak, East Malaysia. These measures are valid and reliable for Malaysian secondary schools and other neighbouring countries taking the cultural aspect into consideration to investigate the nature and dimensions of NPE. These quantitative measures initiated and contributed a new body of knowledge to the NPE in the context of Malaysia other than the conceptual dimensions proposed by Ministry of Education. Practically, the findings, though preliminary in nature, provide school principals and the Ministry of Education with appropriate tools to assess the extent to which school teachers translate and infuse the ideas of the NPE in the day-to-day lesson delivery. Similarly, the measures serve as appropriate instruments for measuring the extent to which school students' capture and internalise the NPE concepts hand-in-hand with academic development.

\section{Limitations and Future Research Direction}

Although findings of these quantitative measures of NPE presented a preliminary sound and reliable measures, several limitations had been driven from the study. One of which was the small sample size on which the analyses were performed. The study sampled 230 participants with 85 variables. Sample size as such did not fulfil the minimum requirement of 5 observations to 1 observed variable as a fundamental requirement for PCA analysis, in addition to the fact that only Sarawak in East Malaysia was sampled. This limitation suggests that future research works should sample larger participants to include the remaining twelve states. This inclusion is necessary for the increment of precision level, the validity of the conclusions reached, generalizability of the findings and meeting the requirement of reasonable representativeness. Moreover, the study was not able to gather opinions of the subject matter experts (SME) concerning the NPE, as such; future replication studies should report SME prior to data collection.

Second, it is clearly evident from the results of the descriptive frequencies that only Malay ethnic group, the Chinese ethnic group and few non-Malaysians participated in the study. Thus the opinions of the Indian ethnic group on the NPE were not obtained in the survey. Given the demographic formation of Malaysians, the study, 
therefore, suggests that future studies should take all necessary measures to include the opinions of the Indian ethnic group in the survey. Since there would be a possible cultural bias playing a significant role in the findings as different ethnic group might hold different perceptions on the same dimensions.

Furthermore, it should be kept in mind the development and validation of any scale requires retesting from a given time to another and in different geographical locations. As such, replication of this preliminary finding of the NPE in different states is highly encouraged.

\section{References}

Abdullah, S., \& Kumar, P. (1990). Pendidikan di Malaysia [Education in Malaysia]. Kuala Lumpur: Longman Malaysia.

Ahmad, R. H. (1998). Educational development and reformation in Malaysia: Past, present and future. Journal of Educational Administration, 36(5), 462-475. http://dx.doi.org/10.1108/09578239810238456

Al-Hudawi, S. H. V., Fong, R. L. S., Musah, M. B., \& Tahir, L. M. (2014). The actualization of the Malaysian national education philosophy in secondary schools: Student and teacher perspectives. International Education Studies, 7(4), 57-68. http://dx.doi.org/10.5539/ies.v7n4p57

Allen, M. (1988). The Goals of Universities. Milton Keynes: SRHE/Open University Press.

Arbuckle, J. L. (2008). AMOS 17.0 user's guide. USA: AMOS development corporation.

Arieh, L. (1978). Regional Meeting of Experts on Examination and other Procedures for the Evaluation of Educational Achievements and Experiments in the Cinctent of Lifelong Education in Europe. 11-16 December 1978. Paris: UNESCO.

Azizah, A. R. (1987). Curriculum innovation in Malaysia: The case of KBSR (Unpublished doctoral dissertation). University of London Institute of Education. United Kingdom.

Bollen, K. A. (1989). A new incremental fit index for general structural equation models. Sociological Methods \& Research, 17(3), 303-316. http://dx.doi.org/10.1177/0049124189017003004

Butler, J. D. (1968). Four Philosophies and their Practice in Education and Religion. New York: Harper \& Row.

Byrne, B. M. (2010). Structural equation modeling with AMOS: Basic concepts, applications, and programing (2nd ed.). New York: Taylor \& Francis Group, LLC.

Che'noh, M. N. (1990). Asas-asas pendidikan: Satu pengenalan [basics of education: An introduction]. Selangor, Malaysia: Flo Enterprise Sdn. Bhd.

Ee, A. M. (1996). Pendidkan di Malaysia 1: Falsafah Pendidikan, Guru dan Sekolah [Education in Malaysia 1: National Philosophy of Education, Teacher and School]. Shah Alam, Malaysia: Penerbit Fajar Bakti Sdn. Bhd.

Fornell, C., \& Larcker, D. F. (1981). Evaluating structural equation models with unobservable variables and measurement error. Journal of Marketing Research, 18(1), 39-50. http://dx.doi.org/10.2307/3151312

Franklin, S. B., Gibson, D. J., Robertson, P. A., Pohlmann, J. T., \& Fralish, J. S. (1995). Parallel analysis: A method for determining significant principal components. Journal of Vegetation Science, 6(1), 99-106. http://dx.doi.org/10.2307/3236261

Ganguli, S., \& Roy, S. K. (2011). Generic technology-based service quality dimensions in banking: Impact on customer satisfaction and loyalty. International Journal of Bank Marketing, 29(2), 168-189. http://dx.doi.org/10.1108/02652321111107648

Hair, F., Anderson, E., Tatham, L., \& Black, C. (2010). Multivariate data analysis (7th ed.). New Jersey: Pearson Prentice Hall.

Hashim, R. (2004). Educational dualism in Malaysia: Implications for theory and practice. Kuala Lumpur: The Other Press.

Hassan, A. (2006). Academic productivity and the impact of the national education philosophy in higher education institutions as viewed by Malaysian academics (Unpublished doctoral dissertation). UK: University of Durham.

Hassan, A., \& Abiddin, N. Z. (2010). How effective should Malaysian national education philosophy be? The Journal of International Social Research, 3(14), 254-262.

Horn, J. L. (1965). A rationale and test for the number of factors in factor analysis. Psychometrika, 30, 179-185. 
http://dx.doi.org/10.1007/BF02289447

International Bureau of Education. (2005). A community of practice as a global network of curriculum developers: Framework Document. Geneva: UNESCO.

Ismail, H., \& Hassan, A. (2009). Holistic education in Malaysia. European Journal of Social Sciences, 9(2). Retrieved May 14, 2014, from http://www.eurojournals.com

Ismail, H., Aida, S. M. Y., Wan, Z. W. A., Ramlah, H., Rosini, A., \& Hapsah, N. (2009a). Belief in God based on the national philosophy of education amongst Malaysian secondary school teachers. European Journal of Social Sciences, 8(1). Retrieved from http://www.eurojournals.com/ejss_9_2_05.pdf

Kline, R. B. (2011). Principles and practices of structural equation modelling (3rd ed.). New York: The Guilford Publications, Inc.

Ministry of Education. (2001). Falsafah pendidikan kebangsaan, matlamatdan misi [national philosophy of education, Goal, and mission]. Putrajaya, Malaysia: Curriculum Development Centre.

Ministry of Education. (2008). Education in Malaysia: A journey to excellence. Malaysia: Educational Planning and Research Division.

Ministry of Education. (2013). Preliminary report: Malaysia Educational Blueprint 2013-2025. Kuala Lumpur. Retrieved January 31, 2014, from http://www.moe.gov.my/userfiles/file/PPP/PreliminaryBlueprint-Eng.pdf

Ministry of Education. (2011). Senarai Sekolah Menengah di Sarawak sepertipada 31 Januari 2011 [List of secondary schools in Sarawak as at 31 January 2011]. Retrieved April 14, 2014, from http://emisportal.m oe.gov.my/emis/emis2/emisportal2/doc/.fckeditor/File/senarai_sekolah_jan2011/menengah/SarawakM.pdf

Molly, N. N. L. (1999). Education in Malaysia: Towards Vision 2020. School Effectiveness and School Improvement: An International Journal of Research, Policy and Practice, 10(1), 86-98.

Morgan, G. A., Leech, N. L., \& Gloeckner, G. W. (2007). Correlation and regression, SPSS for Introductory Statistics: Use and Interpretation. New York: Taylor and Francis Group, LLC.

Nunnally, J. C. (1978). Psychometric theory. New York: McGraw-Hill.

Pallant, J. (2007). SPSS survival manual: A step by step guide to data analysis using SPSS for windows (3rd ed.). England: Open University Press, McGraw-Hill Education.

Sang, M. S. (2008). Pengurusan kurikulum [curriculum management]. Selangor, Malaysia: Penerbitan Multimedia Sdn. Bhd.

Schumacker, R. E., \& Lomax, R. G. (2004). A beginner's guide to structural equation modelling. Mahwah, New Jersey: Lawrence Erlbaum Associates.

Wilson, J. (1977). Philosophy and practical education. London: Routledge \& Kegan Paul Ltd.

Note

Note 1. An evaluation was recently carried out following which improvements were made to the KBSR (Kurikulum Bersepadu Sekolah Rendah), which in turn resulted in the development of KSSR (Kurikulum Standard Sekolah Rendah). More holistic and less examination-oriented for pupils.

\section{Copyrights}

Copyright for this article is retained by the author(s), with first publication rights granted to the journal.

This is an open-access article distributed under the terms and conditions of the Creative Commons Attribution license (http://creativecommons.org/licenses/by/3.0/). 